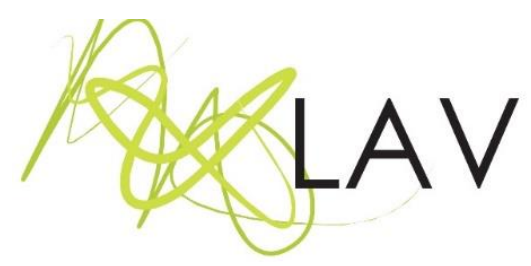

\title{
Ilya e Emilia Kabakov na exposição Not everyone will be taken into the future
}

Ilya and Emilia Kabakov in the exhibition Not everyone will be taken into the future

Viviane Baschirotto ${ }^{i}$ Universidade do Estado de Santa Catarina

\section{Resumo}

O artigo tem como objetivo fazer uma leitura sobre a exposição Not everyone will be taken into the future dos artistas Ilya e Emilia Kabakov que ocorreu na Tate Modern em Londres entre os anos de 2017 e 2018. O texto aborda os gestos artísticos que são persistência e recorrência nas obras apresentadas na exposição: a problemática da História da Arte, a presença de biografias e autobiografias de ficções e verdades e a possibilidade do voo, do escape. A partir dessas questões, pode-se pensar no gesto artístico como algo que sempre retorna na produção de um artista, como uma obstinação e premeditação em suas obras.

Palavras-chave Ilya e Emilia Kabakov, História da Arte, biografia e autobiografia, escape.

\begin{abstract}
The article aims to do a reading about the exhibition Not everyone will be taken to the future, by artists Ilya and Emilia Kabakov, which occurred at Tate Modern in London between 2017 and 2018. The text approaches the artistic gestures that are persistence and recurrence in the works presented in the exhibition: the issue of Art History, the presence of biographies and autobiographies of fictions and truths and the possibility of flying, escaping. From these questions the artistic gesture can be thought as something that always returns in the production of an artist, as an obstinacy and premeditation in his or her works.
\end{abstract}

Keywords Ilya and Emilia Kabakov, History of Art, biography and autobiography, escape.

De outubro de 2017 a janeiro de 2018, a Tate Modern em Londres, Inglaterra, sediou uma exposição retrospectiva dos artistas Ilya e Emilia Kabakov ${ }^{1}$. Dividida em dez salas, a exposição contou com pinturas, instalações, maquetes e objetos que foram criados pelos artistas ao longo de décadas de trabalho. Ilya Kabakov (1933) nasceu em Dnepropetrovsk, na antiga União Soviética. Viveu por 30 anos em Moscou e depois imigrou para os Estados Unidos onde reside atualmente. Estudou arte em

\footnotetext{
1 A exposição também será exibida em St Petersburg, The State Hermitage Museum em 2018 e em Moscou, The State Tretyakov Gallery entre 2018 e 2019.
} 
Moscou, trabalhou por muitos anos como artista oficial do governo soviético, sendo ilustrador de livros infantis. Emilia Kabakov (1945) era sua prima distante, de nascimento na mesma cidade, com o nome de batismo Emilia Lekach Kanevsky. Era uma pianista profissional, estudou literatura na Universidade de Moscou antes de emigrar da União Soviética em 1973. Morou em alguns países até se estabelecer também nos Estados Unidos, onde trabalhou como curadora. A partir de 1989 Ilya e Emilia Kabakov passaram a assinar as obras juntos e alguns anos depois se casaram.

A exposição apresenta obras desde o início dos trabalhos em pintura, e experimentações com materiais de Ilya Kabakov até as últimas instalações dos artistas. Perpassam pela exposição três questões principais que são recorrentes em seus trabalhos: uma ligada a própria História da Arte, relacionada a obra que dá título à exposição, outra conectada a persistência de personagens em seus trabalhos e, outra ainda, articulada a possibilidade de liberdade de escape em diversos trabalhos. O artigo possui caráter bibliográfico, apoiando-se em livros, catálogos e envolvendo também pesquisa de campo com visita a referida exposição.

Cada artista possui um gesto que permanece consigo em sua produção, como uma maneira de fazer, como algo que se repete, uma combinação única de obstinação e premeditação recorrentes em suas obras. A partir do conceito pensado por Giorgio Agamben (2007), em seu texto O autor como um gesto do livro Profanações, podese pensar o gesto artístico como um dispositivo que captura um sentido que sempre retorna nas obras de um artista, como algo que permanece como um sintoma em sua produção. O gesto, apesar de sua recorrência, não faz com que o artista se torne acadêmico dele mesmo, mas sim encontre sempre sua diferença. Nesse sentido, serão abordados os gestos artísticos de Ilya e Emilia Kabakov presentes nas obras da exposição.

\section{Os rastros da História da Arte}

Exibido pela primeira vez na Bienal de Veneza de 2001, Not everyone will be taken into the future (figura 1) é o trabalho que dá nome a exposição de Ilya e Emilia Kabakov e, apesar do nome ser uma frase afirmativa (Nem todos serão levados para o futuro, tradução nossa), é uma obra que suscita alguns questionamentos a respeito da História e da crítica de Arte. A instalação se encontrava na sala de número seis, onde o espectador já havia passado por metade da exposição. Ocupando uma grande sala escura, um suposto vagão de trem está deixando para trás alguns quadros jogados entre a plataforma de embarque e os trilhos. Apoiados na parede e caídos,

Revista Digital do LAV - Santa Maria - vol. 11, n. 1, p. $192-210$ - jan./abr. 2018 ISSN $1983-7348$ http://dx.doi.org/10.5902/1983734830932 
alguns estão rasgando, soltando da moldura, com plásticos e fitas espalhados em volta, como se tivessem sido desembalados ali mesmo. O vagão, por sua vez, tem uma luz difusa acesa internamente e um letreiro em vermelho, que iluminam a sala com a frase que dá nome ao trabalho.

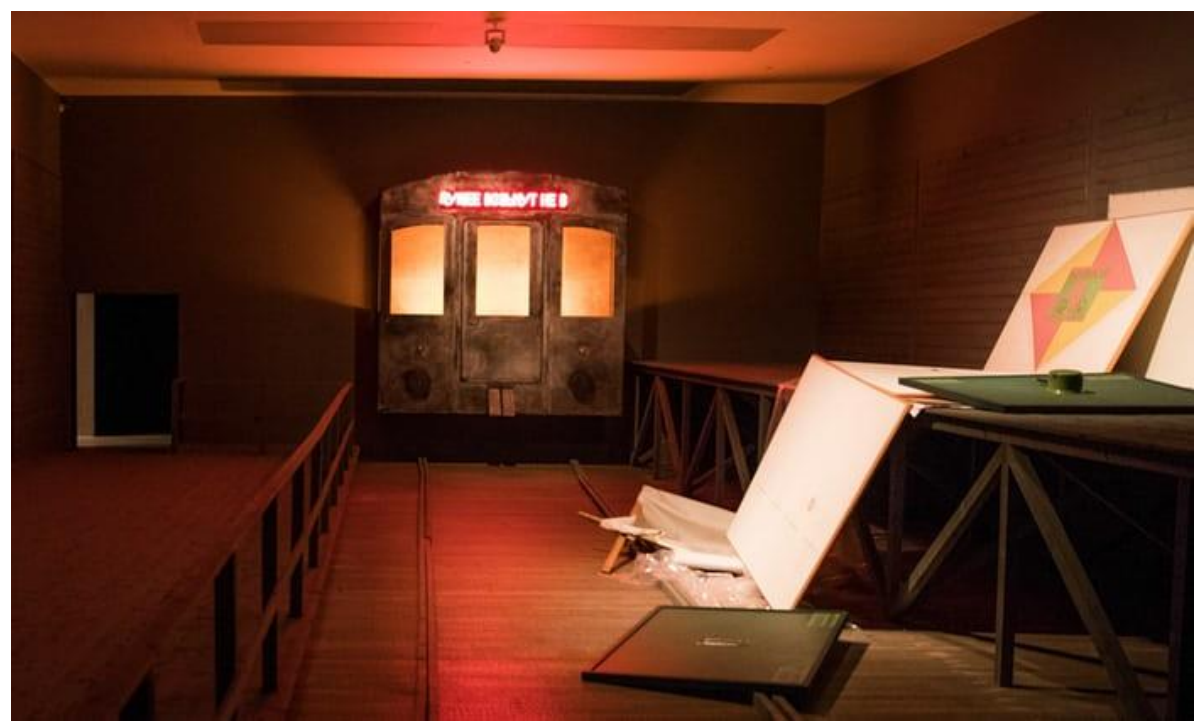

Figura. 01 Ilya e Emilia Kabakov. Not everyone will be taken into the future. 2001, diversos materiais, dimensão variável. MAK - Austrian Museum of Applied, empréstimo permanente de Geyer \& Geyer Collection, Viena. Fonte: www.theguardian.com

O título Not everyone will be taken into the future veio de um texto publicado em $A$ YA, um jornal não oficial sobre arte russa, que Ilya Kabakov escreveu em 1982 onde imagina o artista russo Kazimir Malevich como um líder que poderia levar outros artistas para o futuro. Ilya Kabakov relembra os seus anos de estudante na escola de arte, onde era compelido a seguir o que seus professores pediam ou "você permanecerá aqui"2 (KABAKOV, 2017a, p. 189, tradução nossa). O artista se pergunta como poderia comprar um ticket para esse trem que está partindo, esse trem que leva para um futuro promissor, de uma força vivificante de suprema consciência. E o que acontece com os artistas não promissores? Não terão espaço em seus dormitórios na escola de artes, ao que Ilya Kabakov responde. E termina afirmando que apenas alguns serão levados, escolhidos pelo mestre.

Walter Benjamin vai lembrar que o ferro é um material da modernidade em seu livro das Passagens que o ocupou entre 1927 até sua morte em 1940. Em seu texto Paris, a capital do século XIX Exposé de 1935, Benjamin tece reflexões sobre muitas questões que o livro traz, uma delas o ferro, onde afirma que o trilho de trem é a primeira peça montada em ferro e que sua utilização é evitada em residências, mas

\footnotetext{
2 "you will remain here"
}

Revista Digital do LAV - Santa Maria - vol. 11, n. 1, p. 192 - 210- jan./abr. 2018 ISSN $1983-7348$ http://dx.doi.org/10.5902/1983734831371 
seu uso é encorajado em espaços públicos: "Evita-se o ferro em construções residenciais, mas é utilizado em passagens, pavilhões de exposições, estações de trem - construções que serviam para fins transitórios" (BENJAMIN, 2007, p. 40).

O ferro, para o século XIX, era considerado material de muito valor e era encontrado nos estabelecimentos das passagens comerciais. Logo começou a ser utilizado para construções técnicas e industriais como as estações de trem e seus trilhos. Benjamin nos lembra que o ferro, esse material tão resistente, era utilizado para lugares com fins transitórios, como uma estação de trem. Se fizermos uma analogia com Not everyone will be taken into the future podemos refletir que nessa estação de trem que Ilya e Emilia Kabakov apresenta, as obras de arte estariam tentando entrar nesse trem para escapar de sua transitoriedade e algumas não conseguem.

Com este trem da História da Arte, os questionamentos de como ser um artista com um futuro promissor são lançados para o espectador e esta pergunta se junta a outras sobre o papel da crítica de arte, sobre quem entrará para os anais da História da Arte, quais os artistas que serão lembrados e estudados e o que acontece com essas obras deixadas para trás. Seria aquele o único trem? Talvez outro chegasse daqui a algumas horas e pudesse abrigar essas obras abandonadas. Todavia podemos lembrar que nem mesmo o ferro escapa de levar à transitoriedade.

Pensar os mecanismos da própria História da Arte e seu sistema é um dos gestos recorrentes de Ilya e Emilia Kabakov. Juliet Bingham, curadora da exposição, em seu texto Introduction do catálogo da exposição, afirma que a obra "sinaliza questões fundamentais colocadas pelos artistas sobre a relação com o passado, o lugar do artista na sociedade, o valor da arte e a futura recepção do trabalho de um artista" ${ }^{\prime 3}$. (BINGHAM, 2017, p. 16, tradução nossa). Emilia Kabakov comenta a respeito disso:

Todos os artistas se perguntam se eles são dignos de serem incluídos na história da arte. Mesmo que rejeitem o sistema do museu, eles ainda sonham em estar na coleção do museu. A infância de Ilya foi muito dura. Para ele, o museu era o lugar onde você poderia escapar, ser protegido e onde ninguém poderia encontrar, prejudicar ou punir você. Neste lugar sagrado, você está cercado e protegido pela história da arte, pela fantasia de outros artistas. Você é livre para criar o seu próprio mundo de fantasia4 (BINGHAM, 2017, p. 17, tradução nossa).

\footnotetext{
3 "Signals fundamental questions posed by the artists concerning the relationship to the past, the artist's place in society, the value of art and the future reception of an artist's work."

${ }^{4}$ All artists wonder if they are worthy of being included in the history of art. Even if they reject the museum system, they still dream about being in the museum collection. Ilya's childhood was very harsh. For him, the museum was the place to which you could escape, be protected, and where no one could find, harm
} 
Outro trabalho em exposição e que está em consonância com esses questionamentos é a maquete da instalação Where is our place? ${ }^{5}$ (Onde é o nosso lugar?, tradução nossa) (figura 02), e que imagina duas exposições ocorrendo simultaneamente em uma única galeria de arte, onde nenhuma é totalmente visível para as figuras apresentadas. Uma exposição seria a de quadros de antigos mestres de pintura que estão cortados pela metade pelo teto. A outra seria de fotografias contemporâneas combinadas com poesia expostas na altura dos olhos dos visitantes que aparecem por inteiro na galeria. Existem esses visitantes de estatura convencional para o tamanho da sala e os gigantes, dos quais vemos apenas os pés e parte das pernas.

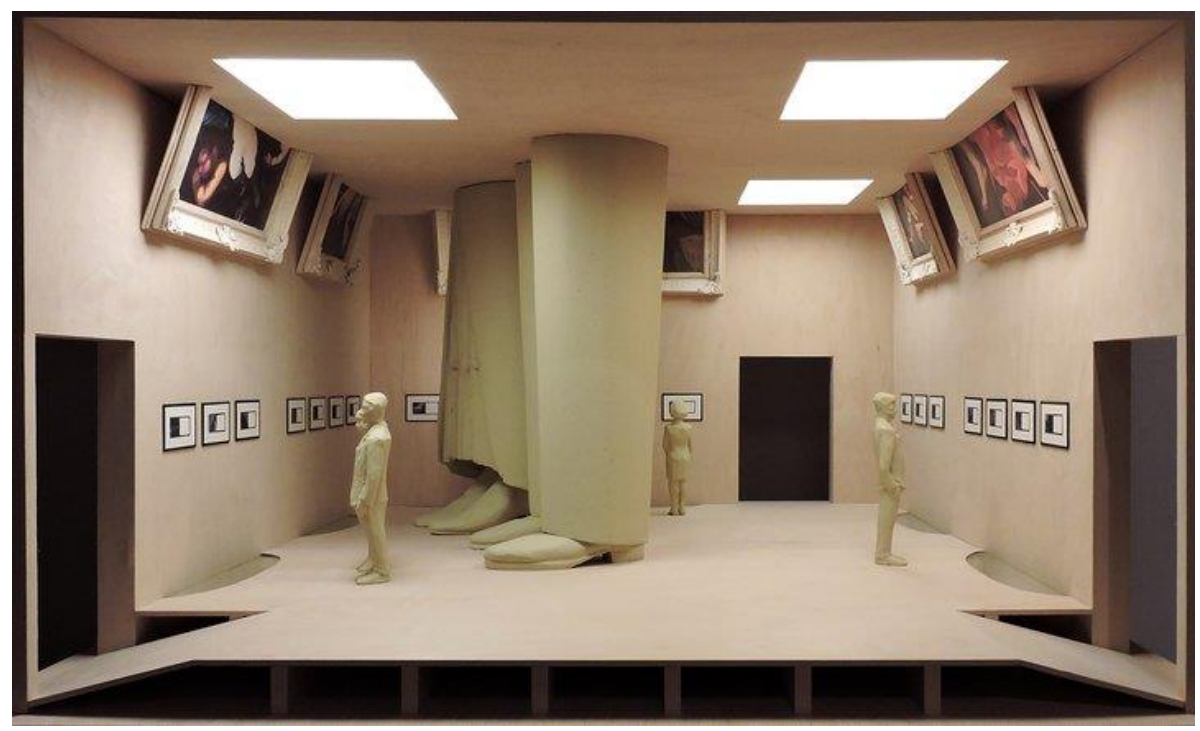

Figura. 02 Ilya e Emilia Kabakov. Where is our place? Modelo de madeira, papel e lâmpadas acesas, 2002/2017. 71 x 114,5 x 114,5 cm. Fonte: www.tate.org.uk

Existe um jogo de escala e percepção em Where is our place? que implica em pensar sobre o papel dos museus no entendimento e na apresentação da História da Arte. Uma questão está posta com seu título: Qual o nosso lugar na História da Arte? Georges Didi-Huberman (2013) em seu texto Questão de detalhe, questão de trecho convida o leitor a ver as obras de arte em detalhes, onde pressupõe uma operação de aproximação, depois de divisão e posteriormente de soma novamente. O autor lembra que Bachelard afirmava que nada era mais difícil de analisar do que fenômenos de grandezas distintas. Lembra as obras de Ticiano, que de longe parecem perfeitas e de perto vê-se borrões e pinceladas grossas. "Em suma, o detalhe coloca antes de tudo a questão: de onde olhar? E aqui não se trata de percepção, mas do pórtico (ou lugar) do sujeito: ali de onde se pensa a pintura" of other artists. You are free to create your own fantasy world.

${ }^{5}$ Where is our place? foi apresentada como instalação no Mori Art Museum em Tokyo no ano de 2004. 
(DIDI-HUBERMAN, 2013, p. 302). Em Where is our place? Nesse lugar que olhamos as obras, vemos algumas apenas pela metade, seria esse mesmo o lugar do qual deveríamos olhar? Onde deveria estar posicionado o sujeito? Qual a escala verdadeira? O que esses gigantes conseguem alcançar com seu olhar que aqui não nos é mostrado? Seriam as obras deixadas para trás?

Didi-Huberman (2013, p. 297) vai afirmar que "a quantidade de coisas que não vemos em uma pintura é desconcertante". O autor fala de obras que podem ser alcançadas com o olhar em sua totalidade e, se esse momento desconcertante acontece mesmo com uma pintura totalmente exposta, o que poderíamos aferir sobre as pinturas pela metade de Where is our place? Detalhar seria necessário, e este detalhe que nos escapa na obra faz parte dela, não estaria perdida e escondida, mas a constitui enquanto totalidade. Didi-Huberman (2013) afirma que Lacan ao tratar do detalhe diz que este é uma alienação. "(...) é uma escolha lógica, uma alternativa na qual somos forçados a perder alguma coisa, de qualquer maneira" (DIDIHUBERMAN, 2013, p. 303, grifo do autor). Existe, portanto, sempre algo que nos escapa nesse olhar, assim como nem tudo é revelado na sala de exposição de Where is our place?

A parte faltante das pinturas pode inclusive ser o que Didi-Huberman (2013, p. 299) chamou de "chave para esgotar o sentido de tudo que é pintado em torno dela", segundo o que reflete sobre o pensamento de Sigmund Freud. Essa inexistência da completude das pinturas poderia dar a ver à completude daquilo a que a obra se propõe: a repensar os espaços expositivos, os museus, a História da Arte. Por que as obras contemporâneas estão inteiras ao alcance do olhar, enquanto as pinturas antigas possuem uma parte obscura e quase não são possíveis de alcançar? A sala de Where is our place? Apresenta essa sobreposição de tempos, de imagens, e se pergunta qual o nosso lugar e qual o lugar das obras dentro da História da Arte.

\section{Biografias e autobiografias, ficções de verdades}

Percorrendo a exposição, na sala de número sete, havia uma porta de tamanho comum para uma casa. Não raro, visitantes passavam direto por esta porta, que era a entrada para Labyrinth (My Mother's Album), (Labirinto (Álbum de minha mãe), tradução nossa) (figura 03). Como o próprio título revela, a obra é em formato de labirinto, com aproximadamente 50 metros de extensão, contendo setenta e seis quadros na parede que contam uma autobiografia da mãe de Ilya Kabakov, Bertha Urievna Solodukhina. O ambiente tem uma iluminação fraca, apenas o suficiente para

Revista Digital do LAV - Santa Maria - vol. 11, n. 1, p. 192 - 210 - jan./abr. 2018 ISSN 1983 - 7348 http://dx.doi.org/10.5902/1983734830932 
ler a biografia da mãe do artista. Além dos textos, cada quadro possui fotografias que retratam a cidade de Moscou mas, principalmente, a cidade ucraniana Berdyansk, na costa do Mar Negro, produzidas pelo tio de Ilya Kabakov, Yuri Grigorevich Blekher, que era fotógrafo. A mãe de Ilya Kabakov foi morar nessa cidade depois de sua aposentadoria em 1959. As fotografias contrastam com o texto, que conta histórias de pobreza, fome e exploração.

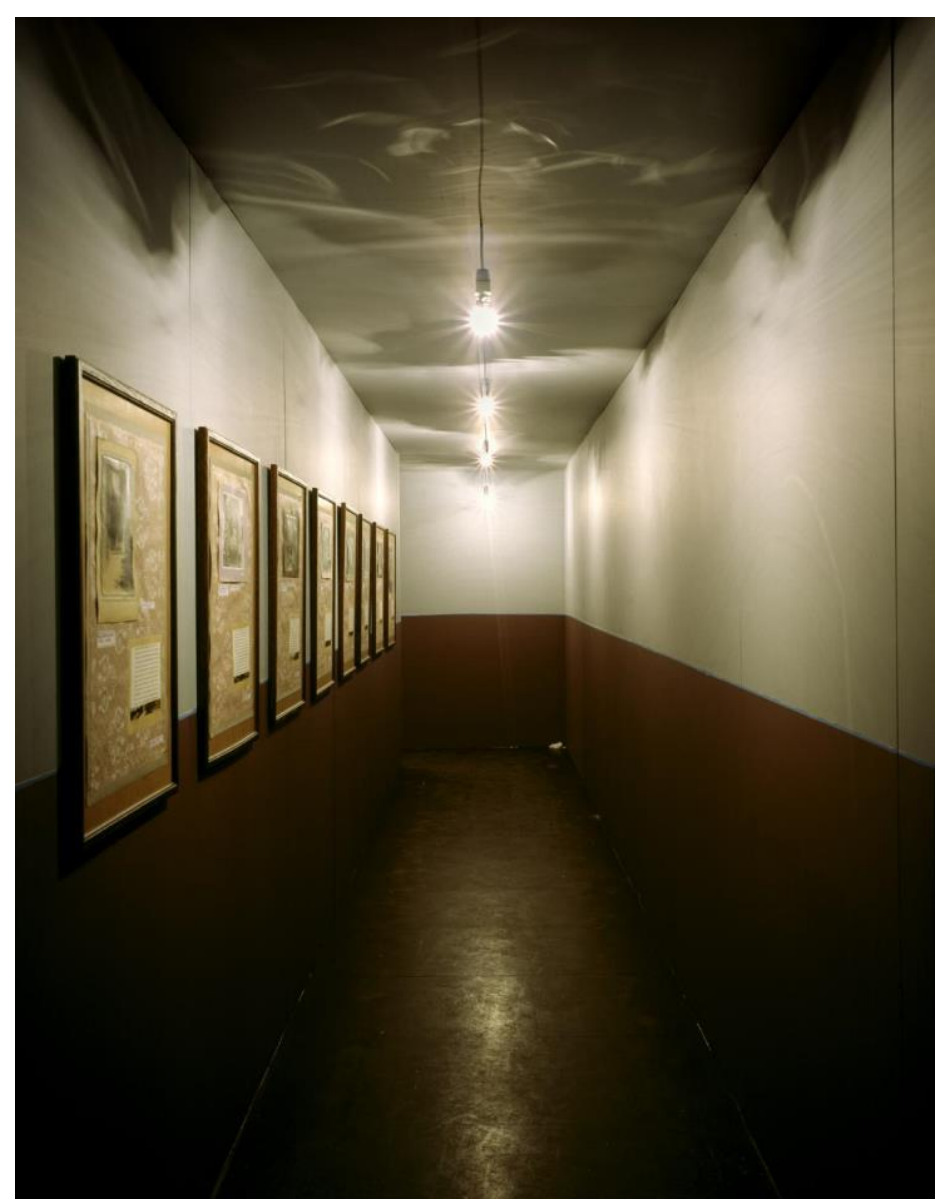

Figura. 03 Ilya e Emilia Kabakov. Labyrinth, My Mother's Album. Instalação. Tate Modern, London, 2000, dimensões variadas. Fonte: www.tate.org.uk

Andando pelo labirinto da obra, acompanhamos a biografia da personagem. Segundo Kate Fowle (2017) em seu texto On Labytinth (My Mother's Album), Solodukhina começa sua história contando sobre seus pais, que eram órfãos e quando tiveram idade legal, se casaram. Conta sobre dois irmãos que morreram logo depois do nascimento e de como sua mãe devotava atenção a ela. Seus pais faleceram quando ainda era jovem. Solodukhina ficou responsável então por seus outros quatro irmãos mais novos e, vivendo em condições precárias, teve um colapso nervoso que a levou a viver por um tempo em um sanatório. Nesse local, conheceu o seu marido, logo engravidou, sofreu um aborto. Quatro anos mais tarde engravidou novamente, levou a gravidez adiante, onde no quadro de número 29 é relatado o nascimento de Ilya 
Kabakov, que nasceu saudável, mas gritava frequentemente por fome. Seu marido, que trazia pouca renda para casa, é descrito como um homem irritado e que depois de algum tempo abandona a família.

A medida que os quadros avançam no labirinto, lemos mais sobre a autobiografia da mãe de Ilya Kabakov. Fowle (2017) lembra que Solodukhina ainda conta que para manter os estudos do filho, se mudaram para cidades maiores, chegando a morar em Moscou. Como ela não tinha permissão para morar legalmente na cidade, mudava-se com frequência para não ser encontrada por policiais, dormindo em um porão úmido ou mesmo em um banheiro em desuso.

A instalação Labyrinth (My Mother's Album) foi apresentada pela primeira vez em Nova York em 1990, um ano depois do falecimento da mãe do artista e este é um dos poucos trabalhos relacionados a sua história pessoal, pois em sua grande maioria, os personagens que Ilya e Emilia Kabakov apresentam são ficcionais. Com poucas inserções de texto de Ilya Kabakov, Solodukhina conta sua história de vida, com alegrias e sofrimentos quando está com 80 anos de idade. A biografia seria essa narrativa de eventos, uma maneira de lembrar, de criar, de ficcionalizar o cotidiano. A vida se encontra dentro dessa narração. Sergio Vilas Boas (2002), no livro Biografias \& Biógrafos, faz uma série de levantamentos que envolvem o processo biográfico, desde questões mais técnicas, como as formas de escrita de uma biografia até mesmo questões éticas na hora de biografar. E no caso de o próprio biógrafo ser o biografado, o autor afirma:

A autobiografia, ao contrário da biografia e da história, argumenta-se pela expressão da consciência. Mas o ato de narrar e de recordar é uma arma contra a solidão e a dor, memória formada de saberes, um saber transmitido e compartilhado (VILAS BOAS, 2002, p. 59).

Também seria uma maneira de expressar sua versão dos fatos, como a memória de Solodukhina sobre como era o relacionamento dos pais, sobre como amava e lutava por seu filho. Vilas Boas (2002, p. 60) completa: "As fronteiras entre imaginação e memória são difíceis de determinar, e as autobiografias e os livros de memórias funcionam como espelhos, autoconhecimento, autocriação e até autodefesa $[\ldots]$ ".

O autor ainda vai lembrar que até o século XVIII não havia biografias dedicadas a uma única pessoa e que a finalidade dessas narrativas era edificar a imagem de alguém pela glória de Deus, sendo que pessoas comuns não eram biografadas com frequência. Em Labyrinth (My Mother's Album), abre-se o espaço para que Solodukhina conte sua história, uma narrativa de pobrezas, incertezas, de cantos escuros, mas também de esperança pelo futuro de seu filho. 
Diferentemente de reis, santos e pessoas nobres, a narrativa biográfica na contemporaneidade abre mais espaço para que as vidas comuns, como a de Solodukhina, sejam contadas. Vilas Boas (2002, p. 18) menciona que "não há certificados epistemológicos para o fazer biográfico", sendo que ela não precisa ser necessariamente apresentada em algum meio específico como impressa em papel, cinema, televisão ou teatro. O que importa seria a compilação de uma vida, o que acontece e se apresenta em Labyrinth (My Mother's Album). Apresentada como obra de arte, o que interessa seria o personagem e sua interpretação, neste caso, uma autopercepção.

O corredor de Labyrinth (My Mother's Album) desembocava na sala nove, onde havia os dez álbuns de Ten Characters (Dez personagens, tradução nossa) expostos cada um em cima de uma carteira com uma cadeira disponível para se sentar e folhear todas as páginas que estavam plastificadas e organizadas como um fichário. A apresentação dos álbuns lembrava a disposição de uma sala de aula. Os álbuns de Ten Characters $^{6}$ foram produzidos entre 1970-74 e contêm escritos, desenhos, biografias e informações sobre dez personagens fictícios criados por Ilya Kabakov, que vivem em um contexto do regime totalitarista da União Soviética.

Cada álbum mostra um fragmento da vida de um personagem fictício, a maioria vive isolado e com pouca esperança. Sitting in a closed Primakov, conta a história de um menino que faz de um armário da sua casa um espaço de imaginação, pensando em como ele poderia voar pela cidade e desaparecer no céu. As imagens contidas nesse álbum revelam o mundo por sua perspectiva, ou seja, mostram o quarto de sua mãe visto por uma fresta do armário, como na figura 04, e também a sua casa, ou mesmo a vista da rua de sua janela. Vilas Boas (2002) menciona que a biografia não necessita ser uma enciclopédia, mas que pode omitir informações para que o entendimento do trabalho seja melhor, assim como nos álbuns apresentados, onde são contadas frações das biografias desses personagens.

The flying Komarov mostra o protagonista e os habitantes de uma cidade que possuem o hábito de voar, contando como é o cotidiano dessa cidade de transeuntes voadores, que vão e voltam do trabalho todos os dias, eventualmente pegando

\footnotetext{
${ }^{6}$ Os álbuns apresentados são: Looking out of the window Arkipov (Olhando para fora da janela Arkipov, tradução nossa), Anna Petrovna has a dream (Anna Petrovna tem um sonho, tradução nossa), Sitting in a closed Primakov (Sentado em um armário Primakov, tradução nossa), The Agonizing Surikov (O agonizante Surikov, tradução nossa), The decorator Malagin (O decorador Malagin, tradução nossa), The flying Komarov (O voador Komarov, tradução nossa), The generous Barmin (O generoso Barmin, tradução nossa), The joker Gorokhov (O piadista Gorokhov, tradução nossa), The mathematical Gorsky (O matemático Gorsky, tradução nossa), The released Gavrilov (O liberado Gavrilov, tradução nossa).
} 
'carona' com pássaros ou asas de aviões e voltando para suas casas ao entardecer, como pode ser observado na página 15 do álbum (figura 05), onde se lê:

'AO ENTARDECER', todos já estão indo para o chão ao escurecer. Nos últimos raios de luz, no entanto, você pode ver aqueles que ainda retornam de viagens distantes, transportando mercadorias de terras distantes, objetos cujo propósito muitas vezes não entendem completamente ${ }^{7}$ (KABAKOV, 2017b, p. 95, tradução nossa).

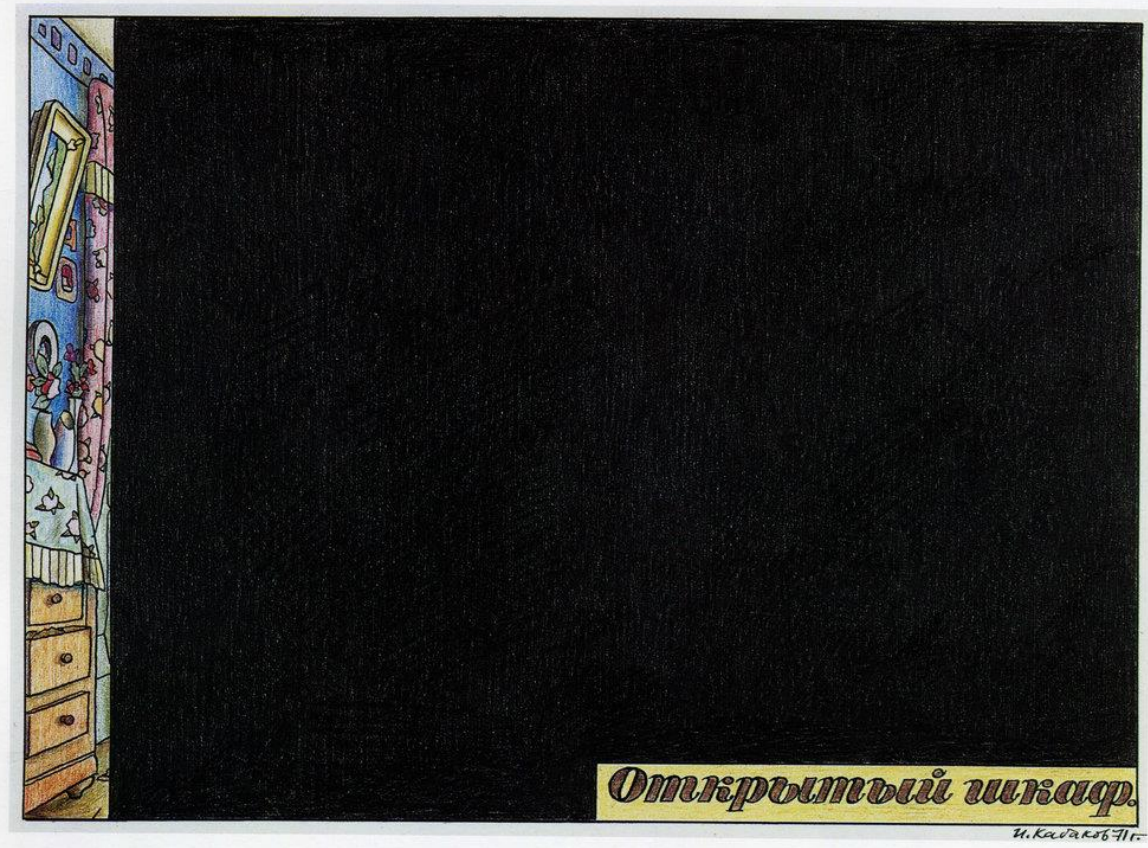

Figura. 04 Ilya Kabakov. Ten Characters. 1972. Sitting in a closed Primakov, página $16,51,5 \times 35 \mathrm{~cm}$ cada página. Tinta e lápis de cor sobre papel. Fonte: www.ilya-emilia-kabakov.com

O álbum termina com a informação de que alguns se tornam simplesmente transparentes, onde logo será possível ver nada além de pássaros voando. Boris Groys em seu texto Re-inventing Authorship vai afirmar que Kabakov faz uma mistura de medo e esperança em Ten Characters, e sobre os álbuns comenta:

Cada um desses álbuns é um livro de folhas soltas que retratam em imagens e palavras a biografia ficcional de um artista que vive nas visões ou nas obras de seus 'heróisartistas' particulares. Todas as imagens têm inscrições comentando sob perspectiva dos vários amigos e parentes de cada artista. A imagem final em cada álbum é uma folha de

\footnotetext{
7 'IN THE EVENING' everybody is already down on the darkening ground. In the last rays of light, however, you can see those who are still returning from faraway journeys, carrying wares from faraway lands, objects the purpose they often fully do not understand.
} 
papel em branco que anuncia a morte do herói ${ }^{8}$ (GROYS, 2017, p. 36, tradução nossa).

Assim também é o final do álbum de The flying Komarov onde os personagens vão se tornando transparentes até não serem mais vistos no céu. Nos álbuns de Ten Characters, os personagens são fictícios, é como se cada um deles criasse um álbum com desenhos e escritos sobre sua vida, são biografias ficcionais. Podem ser pensados como alter egos de Ilya Kabakov, visto que o artista estava habituado, nesse período, a não ser apenas um artista, mas dois. A persistência da abordagem sobre qual é o lugar de um artista na História da Arte pode ocorrer também em função de que Ilya Kabakov, quando ainda não havia emigrado da Rússia e ainda morando em Moscou, trabalhava tanto como artista oficial como não oficial na antiga União Soviética. Como artista oficial, a partir da década de 1950, Ilya Kabakov fazia ilustrações de livros infantis dentro do padrão aceito marcado pelo Realismo Socialista, com isso conseguia se manter como artista e manter um ateliê de trabalho. Como artista não oficial, era membro de um grupo de artistas fora do sistema de arte soviética conhecido como Moscow Conceptualims, um movimento que aconteceu por volta das décadas de 1960 e 1970 e que possuía um retorno ao realismo. Os artistas possuíam interlocução seletiva, eram poucas as pessoas que podiam ver seus trabalhos além deles mesmos. Assim, como artista não oficial, não teria garantia nenhuma de que seu trabalho seria levado para o futuro e que dele restaria alguma coisa nos anais da História da Arte.

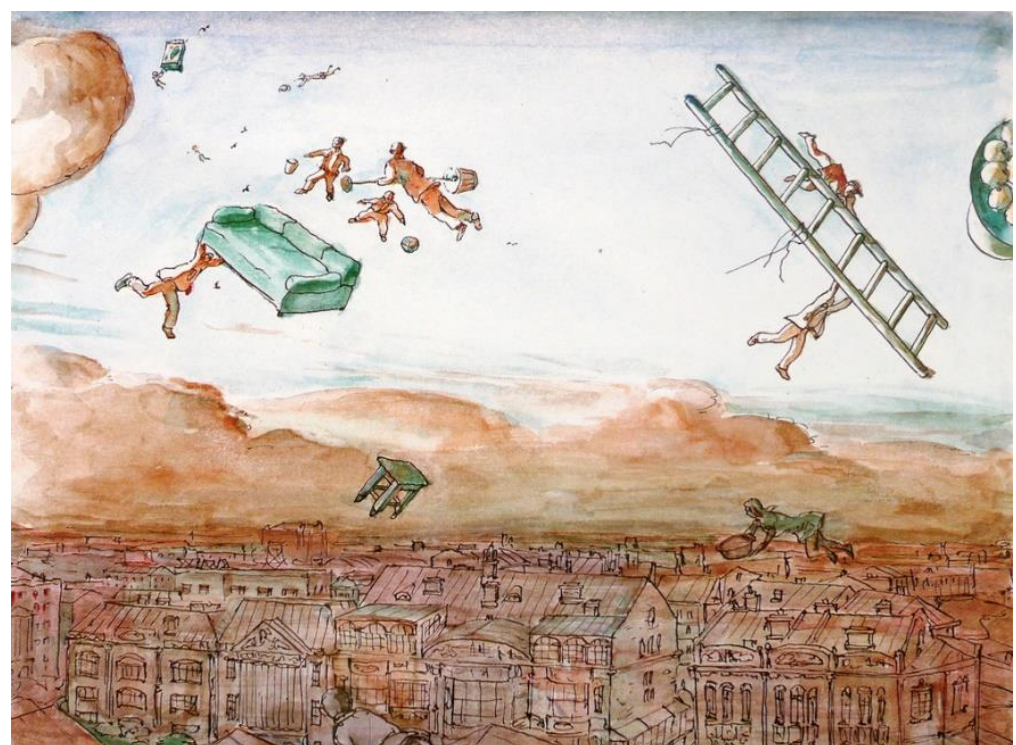

Figura. 05 Ilya Kabakov. Ten Characters. 1970/1994. The flying Komarov, página $15,51,5 \times 35 \mathrm{~cm}$ cada página. Tinta e lápis de cor sobre papel. Coleção privada. Fonte: http://www.ilya-emilia-kabakov.com.

\footnotetext{
8 "Each of these albums is a book of loose sheets depicting in images and words the ficcional biography of an artist living on the visions or works of their particular 'artist-heroes'. All the images bear scriptions commenting from the perspective of the various friends and relatives of each artist. The final image in every album is a sheet of white paper announcing the death of the hero."
} 
Depois dos álbuns de Ten Characters, surgiram dezenas de outros personagens nas obras de Ilya e Emilia Kabakov. Muitos deles são outros artistas, que podem ser descritos nas obras e histórias como sem talento ou mesmo desesperados. Ten Characters também é o título de uma instalação produzida em 1989 em Nova York, mas com outros dez personagens, nenhum deles se repete com os do álbum criado anos antes. A criação de personagens, biografias e autobiografias é, portanto, mais uma das recorrências e persistências no gesto artístico dos artistas.

Labyrinth (My Mother's Album) e Ten Characters apresentam biografias, a diferença e a semelhança entre as obras está no regime de verdades apresentado por elas. Enquanto Labyrinth (My Mother's Album) é uma autobiografia da mãe de Ilya Kabakov apresentada como instalação pelos artistas, Ten Characters é um conjunto de biografias ficcionadas. Vilas Boas (2002) afirma em diferentes partes de seu livro que quem deve enxergar a extraordinariedade do biografado é o biógrafo e que "as pessoas extraordinárias excitam, orientam, alertam, ajudam a vivenciar o que acontece como se acontecesse conosco, dando dimensão imaginária à vida" (VILAS BOAS, 2002, p. 39). Fiç̧ão e verdade se encontram quando não podemos nos certificar dos limites entre uma e outra. A certeza reside no fato de que se são, de alguma maneira, perjúrio ou realidade, seus trabalhos são, antes de mais nada, obras de arte.

\section{A possibilidade do escape}

Presente em algumas obras da exposição, o voo e a possibilidade do escape se torna mais uma questão recorrente nos trabalhos de Ilya e Emilia Kabakov. Logo no começo da exposição, na sala três, a instalação The man who flew into space from his apartment ( $O$ homem que se ejetou de seu apartamento para o espaço, tradução nossa) (figura 06), apresenta a história de um homem que supostamente se catapultou de seu apartamento para o espaço. Em seu quarto encontramos um buraco no teto, sua catapulta, e uma espécie de maquete do bairro onde vivem, com o apartamento comunitário. Ele calculou que chegaria a 40 metros da Terra, chegando no espaço e alcançando uma outra dimensão. Em seu quarto há muitos pôsteres sobre a temática do espaço e que permeiam o contexto da corrida espacial que se deu entre Rússia e Estados Unidos no fim do século passado durante a Guerra Fria. Em seu livro Ilya Kabakov: The man who flew into space from his apartment, Borys Groys (2006) vai afirmar que o experimento parece ter sido um sucesso, já

Revista Digital do LAV - Santa Maria - vol. 11, n. 1, p. 192 - 210 - jan./abr. 2018 ISSN 1983 - 7348 http://dx.doi.org/10.5902/1983734830932 
que não vemos o corpo do homem no cômodo e que as viagens espaciais eram uma forma de sonho coletivo para atingir um êxtase. O voo para o cosmos seria essa chance individual e coletiva de uma experiência de elevação.

A possibilidade de voar, como em The man who flew into space from his apartment aparece em diversos outros trabalhos, como no álbum The flying Komarov anteriormente citado, ou mesmo em outros desenhos e pinturas. Esse gesto foi apresentado com maior enfoque na última sala da exposição, de número dez, como se fosse uma forma de epifania dessa mostra retrospectiva, como se depois de passar por tantas outras salas e ter tantas informações à disposição, agora o visitante estava chegando em um lugar mais elevado e pudesse quase tocar o céu.

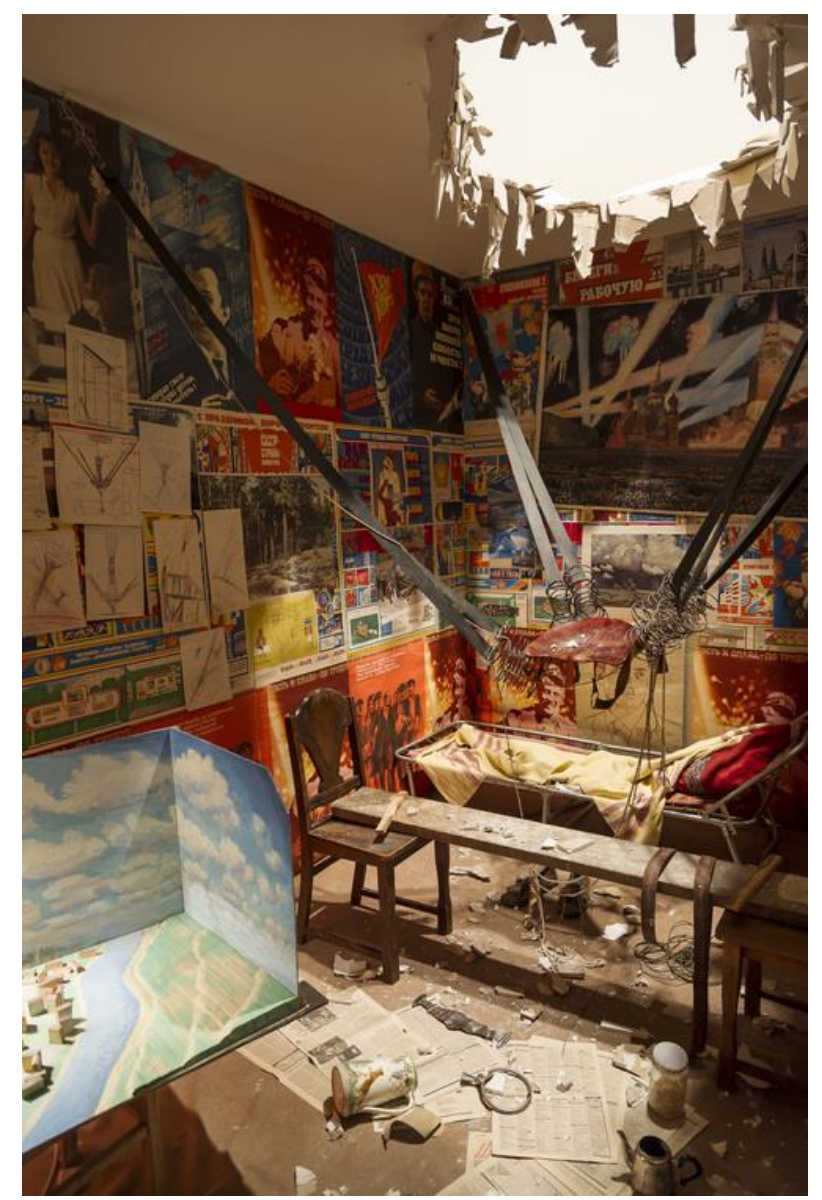

Figura. 06 Ilya Kabakov. The man who flew into space from his apartment. 1988. Instalação. Fonte: www.tate.org.uk

Na exposição temos uma experiência quando passamos de uma sala para outra. Jacques Derrida (2012) em seu livro Pensar em não ver aborda a experiência como uma viagem sem desígnio, como uma travessia, esse experimentar rumo a. Derrida escreve muito sobre a experiência, sobre como o pensamento, a interpretação de algo que ocorre na experiência, que a experiência do acontecimento é imprevisível e que sempre corremos o risco de neutralizar a experiência do acontecimento pelos 
nossos olhos, por aquilo que antecipa. "Experiência do acontecimento é uma experiência passiva, rumo à qual, e eu diria contra a qual, acontece o que não se vê vir, e que é saída totalmente imprevisível, não pode ser predito" (DERRIDA, 2012, p. 70). O outro me surpreende quando eu não o vejo ainda, completa Derrida, assim como as obras, que vão se encadeando entre uma sala e outra e então podemos ter o acontecimento de uma experiência na exposição.

Nesta última sala a figura do anjo é a mais explorada, como alguém sem lugar na terra, um ser apátrida, longe das restrições e burocracias impostas na Terra. No modelo para instalação que pode ser visto na figura 7, How to meet an Angel (Como conhecer um anjo, tradução nossa), uma grande estrutura de madeira toma conta do centro da sala de exposição. Acima de sua base, há uma casa e ao lado uma torre de madeira com uma escada que vai desde a base e ultrapassa a torre construída, sendo elo de ligação entre uma figura humana em sua ponta e o anjo que desce do céu a seu encontro e, acima dele, a iluminação de toda cena.

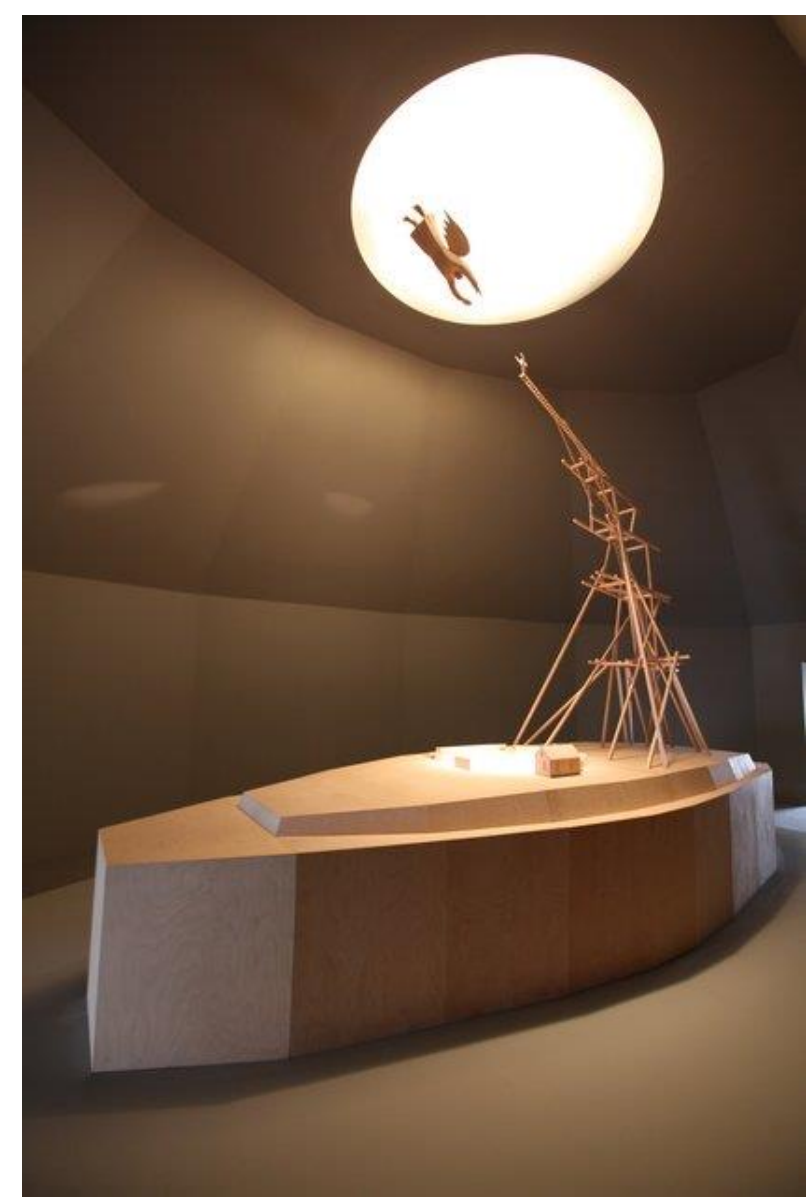

Figura. 07 Ilya e Emilia Kabakov. Modelo de How to meet na Angel. 1988/2002. Madeira, metal, figuras de madeira e fio transparente. Dimensões variáveis. Coleção privada. Fonte: www.tate.org.uk 
O texto que acompanha o trabalho explica como é possível que uma pessoa possa encontrar seu anjo, que possa ter a experiência deste encontro: "Tudo o que é necessário é lembrar que esse encontro pode ocorrer em circunstâncias extremas, e especialmente em momentos críticos na vida de uma pessoa"9 (KABAKOV, 2017, p. 182, tradução nossa). A seguir, o texto dá as instruções sobre como isso é possível, que a escada deve ter um alcance de 1.100 metros e que a pessoa que estiver disposta a subir a escada deve dispor de pelo menos dois dias para isso. Uma vez em seu topo, a pessoa estará acima das nuvens, sozinha em um clima rigoroso, e o anjo aparecerá em razão desse pedido de ajuda urgente, será inevitável a sua aparição, no momento da experiência, onde algo não se vê vir. "A experiência é o que nos relaciona à apresentação do presente: algo se apresenta, temos a experiência disso" (DERRIDA, 2012, p. 79). Um anjo se apresenta, então temos a experiência desse encontro.

How to meet an Angel nos traz um certo tipo de manual para que todos possam, em algum momento de desesperança, ter a experiência desse encontro com um anjo. $A$ escada serve como ponte, do chão ao céu, dos problemas e catástrofes da Terra para esse cosmos de felicidade.

A metáfora do voo é aquela a que os Kabakov se voltam repetidamente: o céu como uma rota para escapar, o desaparecimento, o vôo cósmico, os anjos de diferentes formas e a busca da sabedoria e da felicidade ${ }^{10}$ (BINGHAM, 2017, p. 15, tradução nossa).

Walter Benjamin (1994) em seu texto Sobre o conceito de história, escrito em 1940, reflete sobre o discurso a respeito da história onde critica a forma progressista e historicista como pensamento cronológico e linear, onde a ideia de progresso está relacionada a ideia de um tempo vazio e homogêneo. Benjamin (1994) utiliza a pintura Angelus Novus de Paul Klee para pensar o anjo da história, em que seu rosto estaria dirigido para o passado, e vê uma catástrofe aonde estaríamos vendo uma evolução para algo melhor. Há apenas ruína, e uma tempestade o impele para o futuro, este seria o progresso. Rod Mengham em seu texto The archeo-futures of Ilya and Emilia Kabakov vai afirmar que a resposta de Ilya e Emilia Kabakov ao anjo da história de Benjamin, apanhado olhando para trás em desespero seria

[...] o indivíduo voltado para o futuro de How to meet an angel $[\ldots]$, esticando cada tendão na tentativa de transfiguração do

\footnotetext{
9 "All that is necessary is to recall that this encounter can take place in extreme circumstances, and specially at critical moments in a person's life."

10 "The metaphor off light is one to which the Kabakovs repeatedly turn: the sky as a route to escape, disappearance, cosmic flight and angels in different guises, and the search for wisdom and happiness."
}

Revista Digital do LAV - Santa Maria - vol. 11, n. 1, p. 192 - 210- jan./abr. 2018 ISSN $1983-7348$ http://dx.doi.org/10.5902/1983734831371 
dedo - ao estilo Michelangelo - aparentemente em oferta de um anjo graciosamente condescendente que passa a cruzar o passado $^{11}$ (MENGHAM, 2017, p. 59, tradução nossa).

Benjamin (1994) ainda afirma que a imagem de felicidade está ligada à imagem da salvação, como podemos pensar que How to meet an Angel se apresenta, na possibilidade desse encontro de felicidade e redenção. Na mesma sala de How to meet an Angel se encontra o trabalho How can one change oneself? (Como se pode mudar, tradução nossa) (figura 08) que apresenta asas de anjos feitas de penas fixadas em um colete. Ao lado um desenho e um texto que começa com a pergunta: "Como você pode se tornar melhor, mais gentil, mais decente?"12 (KABAKOV e KABAKOV, 1998, tradução nossa). A seguir, o texto pontua que algumas possibilidades que as pessoas veem para mudar são através do eu pessoal, seguindo as leis morais ou mesmo por meio da religião. Nenhuma delas estaria errada. Todavia o texto segue agora como um manual de instruções para a confecção de asas, da maneira como vemos elas nesse quadro. O texto afirma que é necessário colocar as asas e se sentar em silêncio por alguns minutos, repetindo isso por algumas semanas, até que o efeito das asas brancas se manifeste. No desenho ao lado, vemos a ilustração de um homem que parece estar seguindo as orientações descritas.

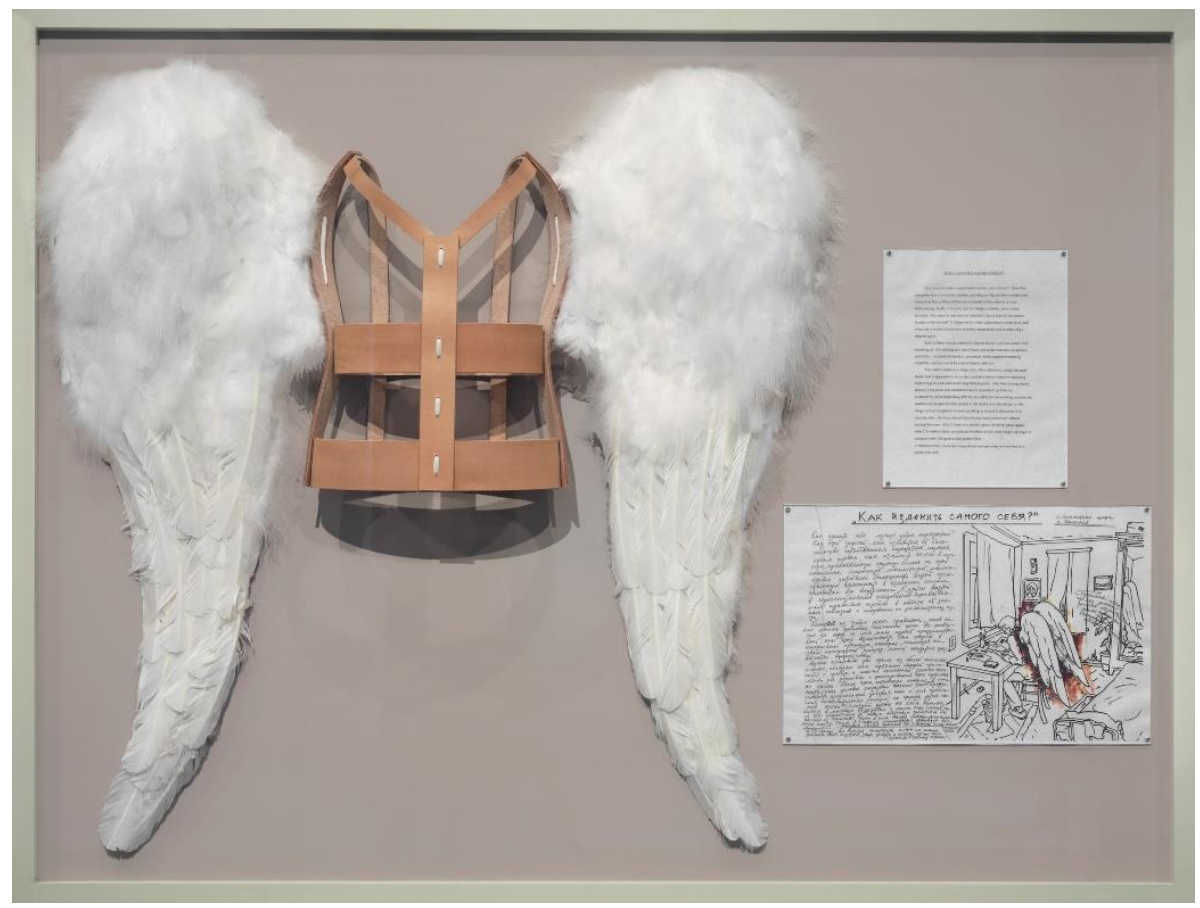

Figura. 08 Ilya e Emilia Kabakov. How can one change oneself? 1998. Penas, couro e tinta sobre papel. $109 \times 142 \mathrm{~cm}$. Coleção privada. Cortesia de Galerie Thaddaeus Ropac, Londres, Paris, Salzburg. Fonte: www.tate.org.uk

11 "[...] the forward-looking individual of How to meet an angel [...], stretching every sinew in his attempt at the fingertip transfiguration - Michelangelo - style - seemingly on offer from a graciously condescending angel who happens to be cruising past."

12 "How can you make yourself better, kinder, more decent?" 
A partir do título da obra e da descrição presente no quadro, podemos pensar que para mudar a si mesmo, uma possibilidade seria se tornar um híbrido entre humano e anjo, que aqui vem acompanhado da ideia de pureza e leveza. Tanto em How to meet an Angel quanto em How can one change oneself? manuais são apresentados para que se possa encontrar um anjo ou mesmo tornar-se alguém melhor, tendo o anjo como ponto de referência e partida. O céu e os anjos nas obras de Ilya e Emilia Kabakov, são como presentificação da possibilidade de escapar de uma vida de miséria, tragédia, burocracias e regras. Existe uma maneira de escapar, seja se catapultando de seu apartamento para o espaço, subindo uma escada que leva até o céu e lá encontrando o seu anjo, ou mesmo tomando a energia de um anjo, deixando que suas asas ajam sob si mesmo e o torne uma pessoa melhor. Existe nas obras essa menção de liberdade, a possibilidade de algo melhor acontecer, de que o céu seria esse lugar de suspensão, de epifania.

Benjamin (1994) afirma que é preciso pensar a história como um tempo heterogêneo, atando vínculos com o passado, o presente e o futuro. Há uma percepção de perfeição associada ao futuro, ao futuro que The man who flew into space from his apartment, How to meet an Angel e How can one change oneself? apresentam. As figuras que os artistas mostram nessas obras estão tentando ir para esse futuro, apresentado na metáfora do voo, do escape. Seria talvez esse o mesmo futuro do qual Not everyone will be taken into the future se trata, desse futuro onde um artista pode ser melhor, se seguir algumas instruções. Um futuro como possibilidade de escape da realidade, o futuro contido nos anais da História da Arte.

\section{Considerações}

A exposição Not everyone will be taken into the future consegue fazer um apanhado de questões que são persistências no trabalho dos artistas. O gesto, como lembra Agamben (2007) seria essa presença incongruente e estranha. Ao mesmo tempo que mostra as obras deixadas para trás pelo trem que pode ser visto como o trem da História da Arte, as obras da exposição fazem um esforço de permanência e apresentam maneiras de escape dessa destruição, desse esquecimento. Seus gestos artísticos como traços de persistência são apresentados quando estão evidenciando questões sobre a História da Arte, os regimes de verdades das ficções e biografias e a possibilidade de escapar e ir para o futuro. São questões que contaminam umas as outras, são diferentes traços que podem estar presentes em uma mesma obra. Os 
gestos presentes das obras de Ilya e Emilia Kabakov são dispositivos que acionam o sentido de desejo de permanência expresso em suas obras.

A exposição impõe muitas perguntas e, mesmo assim, nos coloca a afirmativa com o seu título, de que nem todos serão levados para o futuro. A História da Arte seria como esse trem, de base sólida como o ferro, mas que trabalha com a transitoriedade. Para escapar dessa condição, as obras inscrevem biografias e ficções para contar fatos, histórias de pessoas que existem e que são invenções, fazendo com que o espectador se encontre em um território movediço entre o perjúrio e a verdade. Também refletem sobre a própria condição da História da Arte, os anjos nas obras dos artistas são apresentados como metáfora da possibilidade de escape da catástrofe, sofrimento e miséria, concentrando-se naquilo que pode ser o sublime, nesse encontro e experiência com o futuro, com aquilo que não se vê vir. O desejo das obras de Ilya e Emilia Kabakov é escapar à efemeridade e transitoriedade, evidenciando um gesto que implica em permanência.

\section{Referências}

AGAMBEN, Giorgio. O autor como um gesto. In: Profanações. São Paulo: Boitempo, 2007.

BENJAMIN, Walter. Sobre o conceito de história. In: Magia e técnica, arte

e política: ensaios sobre a literatura e a história da cultura. Obras escolhidas Volume 1. 7a edição. São Paulo: Brasiliense, 1994.

. Paris, a capital do século XIX Exposé de 1935. In: Passagens.

Belo Horizonte; São Paulo: Ed. UFMG; Imprensa Oficial do Estado de São Paulo, 2007.

BINGHAM, Juliet. Introduction. In: BINGHAM, Juliet (org.). Not everyone will be taken into the future. Londres: Tate Publishing, 2017.

DERRIDA, Jacques. Pensar em não ver. Florianópolis: Ed. da UFSC, 2012.

DIDI-HUBERMAN, Georges. Questão de detalhe, questão de trecho. In:

Diante da Imagem. São Paulo: Editora 34, 2013.

FOWLE. Kate. On Labyrinth (My Mother's Album). In: BINGHAM, Juliet (org.). Not

everyone will be taken into the future. Londres: Tate Publishing, 2017. 
GROYS, Boris. History Becomes Form, Moscow Conceptualism. Cambridge:

The MIT Press, 2010.

Ilya Kabakov: The man who flew into space from his apartment.

Londres: Afterall Books, 2006.

HALL, Neil. Not everyone will be taken into the future. Disponível em: $<$ www.theguardian.com>. Acesso em: 26 fev. 2018.

KABAKOV, Ilya; KABAKOV, Emilia. Albums. Disponível em: <http://www.ilyaemilia-kabakov.com>. Acesso em: 26 fev. 2018.

.How can one change oneself. Obra de arte. 1998.

How to meet your angel. In: BINGHAM, Juliet (org.). Not everyone will

be taken into the future. Londres: Tate Publishing, 2017.

KABAKOV, Ilya. Not everyone will be taken into the future. In: BINGHAM, Juliet

(org.). Not everyone will be taken into the future. Londres: Tate Publishing, 2017a.

The flying Komarov. In: BINGHAM, Juliet (org.). Not everyone will be taken into the future. Londres: Tate Publishing, 2017b.

MENGHAM, Rod. The archeo-futures of Ilya and Emilia Kabakov. In: BINGHAM, Juliet (org.). Not everyone will be taken into the future. Londres: Tate Publishing, 2017.

TATE. Disponível em: <www.tate.org.uk>. Acesso em: 26 fev. 2018.

VILAS BOAS, Sergio. Biografias \& Biógrafos: jornalismo sobre personagens. São Paulo: Summus, 2002.

i

Doutoranda em Teoria e História da Arte no PPGAV UDESC. Mestre em Artes Visuais pelo Programa de Pós-Graduação em Artes Visuais da Universidade do Estado de Santa Catarina (UDESC, Florianópolis, Brasil). Pós-graduada em História da Arte (UINIVILLE). Graduada em Licenciatura em Artes Visuais (UNIVILLE). Atualmente é bolsista PROMOP (Programa de Monitoria de Pós-Graduação) e membro da equipe editorial da Revista Palíndromo vinculada ao PPGAV UDESC. Professora de cursos livres e disciplinas na área de História da Arte. baschirottoviviane@gmail.com

Como citar esse artigo:

BASCHIROTTO, Viviane. Ilya e Emilia Kabakov na exposição Not everyone will be taken into the future. Revista Digital do LAV, Santa Maria: UFSM, v. 11, n. 1, p. 192-210, jan./abr. 2018.

Enviado em: 01 de março de 2018 / Aprovado em: 20 de março de 2018.

Revista Digital do LAV - Santa Maria - vol. 11, n. 1, p. 192 - 210- jan./abr. 2018 ISSN $1983-7348$ http://dx.doi.org/10.5902/1983734831371 